\title{
Articles
}

\section{The Dynamic Process of Being (a Person): Two Process-Ontological Theories of Personal Identity}

\author{
Daniel Robert Siakel
}

Daniel Robert Siakel is in the Department of Philosophy at University of California, Irvine. <Daniel.robert.siakel@gmail.com>

ABSTRACT: The purpose of this article is to introduce, interpret, and develop two incompatible process-ontological theories of personal identity that have received little attention in analytic metaphysics. The first theory derives from the notion of personal identity proposed in Alfred North Whitehead's metaphysics, but I interpret this notion differently from previous commentators. The Whiteheadian theory may appeal to those who believe that personal identity involves an entity or entities that are essentially dynamic, but has nothing to do with diachronic objectual identity: the (putative) binary equivalence relation that every entity bears to itself, and only to itself, even after undergoing intrinsic change. The Whiteheadian theory may also find favor with those who, like Whitehead, reject the possibility of pure processes and hold that in every becoming, something — which need not be an object, thing, or individual substance-becomes. The second theory derives from the notion of recurrent dynamics presented in Johanna Seibt's General Process Theory. The Seibtian theory may appeal to those who believe that personal identity involves not only an entity or entities that are essentially dynamic, but also the relation of diachronic objectual identity. The Seibtian theory may also find favor with those who, like Broad and Sellars, find reason to postulate pure processes.

\section{The Problem of Personal Identity}

The so-called "persistence problem" of personal identity-how persons can survive intrinsic change-is an instance of the more general problem of persistence: how temporal entities can survive intrinsic change. For this reason, most solutions to the persistence problem of personal 
identity accord with one of two general theories of persistence: endurantism, which is associated with three-dimensionalist conceptions of time and change; or perdurantism, which is associated with four-dimensionalist conceptions of time and change.

Theorists (e.g. Gallois) often formulate the persistence question of personal identity in the following way: What is it for a person existing at one time to be identical to a person existing at another?

To avoid charges of question-begging "person essentialism" (Olson), some prefer to formulate the question as follows: Under what possible circumstances is a person who exists at one time identical with something that exists at another time (whether or not it is a person then)?

Both formulations make it seem as if the relation of identity must enter into one's account of how one and the same entity - in this case, a person-remains one and the same over time. Given the widely recognized ambiguity of the terms "identity," "one," and "same," however, we need to clarify what "identity" is supposed to mean in this context.

Many theorists maintain that the kind of identity that is relevant to the persistence of persons is the extensionally unique, binary equivalence relation that one entity bears to itself and only to itself even after it undergoes intrinsic change. Following Wehmeier, we can refer to this putative relation as "diachronic objectual identity," meaning the binary equivalence relation that every entity bears to itself and only to itself over some span of time.

Other theorists have resisted the claim that persistence of persons involves objectual identity. Hume, for example, proffers an empiricist theory of personal identity according to which the self is nothing over and above (or below) a bundle of perceptions. Perry, to provide another example, has argued that the relation which is most relevant to the persistence of persons is not identity per se, but non-transitive unity relations that obtain between distinct person-stages. Similarly, Parfit has argued that the relation of identity is not "what matters" in our concerns about personal identity, but rather that what matters are relations of psychological connectedness and continuity.

The issue as to whether personal identity involves objectual identity is indeed essential, but it is not the only issue that is pertinent to the persistence of persons. Another crucial question - which I will pursue here-is what kind of entity a person is, such that it can survive change. The consensus has been that persons are either individual substances or substance-like 
particulars. (Since "substance" is said in many ways: I mean the former to include both traditional substances and non-traditional bundles, and the latter to include four-dimensional space-time worms and/or stages.) Here I will introduce and develop two novel and under-appreciated-indeed, virtually ignored - theories of personal identity, which attempt to explain how persons persist in consonance with the premise that processes, and not substances or substance-like particulars, are ontologically fundamental. As we will see, the two theories diverge on several important points, including whether the persistence of persons (as processes) involves objectual identity, whether the notion of process is essentially temporal, and so on. I have chosen to focus on these and not other process-ontological theories: first, because they are rigorous, in that they form just part of a process-philosophical system; second, because of their actual and potential influence (in process philosophy and analytic metaphysics, respectively); and third, because each employs a novel, contentious conception of processes that affords fruitful comparison with familiar theories.

To begin, I will briefly introduce-but neither evaluate nor endorse-some benefits that process-ontological theories of personal identity are supposed to have over rival theories.

\section{Process-Ontological Motivations}

To adequately explain how persons persist, a theory of personal identity must specify what kind of entity a person is. One familiar view takes persons to be substances of some kind; that is, entities which are existentially independent, can remain essentially the same even when undergoing change, and serve as the basis, substrate, or bearer of a person's accidental properties, which change over time. Another common view takes personal identity to amount to identity of consciousness, rather than identity of substance, and attempts to provide necessary and sufficient conditions for what counts as one and the same consciousness over time. A third kind of view takes persons to be bundles or strings of closely connected entities, such as perceptions (Hume), instantaneous "subjects of experience-as-single-mental-thing" (G. Strawson), or person-stages (Sider). A fourth kind of view rejects the existence of persons altogether.

Process-ontological theories of personal identity do not fall neatly into any of these kinds. The reason is that process ontologists address the problem from a radically different perspective, according to which the 
basic building blocks of the universe are processes, and not substances or substance-like particulars. Accordingly, process ontologists generally maintain that a person is not a substance or substance-like particular that endures (three-dimensionally) or perdures (four-dimensionally), but rather is an essentially dynamic phenomenon that is individuated by how it functions - where unity and continuity, as we will see, are principal ontological features of such functioning.

Rescher and others have claimed that process ontology is especially germane for capturing the nature of personhood, since

People generally incline to see themselves and their doings in processual terms as sources of teleological, agency-purposive activities geared to the satisfaction of needs and wants as they appear in the circumstances of the moment. In application to ourselves, at any rate, static thing-classifiers are naturally distasteful to us. (Rescher 14)

In this way, process ontology is supposed to bypass the epistemic difficulty of ascertaining what we are (statically), by conceiving of what we are in terms of what we do (dynamically). As Rescher puts it,

There is no problem with experiential access to the processes and patterns of process that characterize us personally-our doings and undergoings, either individually or patterned into talents, skills, capabilities, traits, dispositions, habits, inclinations, and tendencies to action and inaction are, after all, what characteristically define a person as the individual he or she is. (Rescher 15)

That said, there are at least four considerations that motivate Rescher and others to propose process-ontological theories of personal identity. (To reiterate, I will not evaluate these considerations here, for I am interested only in what has motivated some metaphysicians to take this relatively "revisionary" route.)

First, conceiving of a person as a structured system of processes is supposed to accord with how we think about ourselves; namely, as relatively stable centers of agency defined by what we do (dynamically), rather than what we are (statically). Second, process-ontological theories purportedly do not require us to postulate mysterious, experientially inaccessible, ad hoc unifying substances; nor do they require us to postulate mysterious relations in virtue of which static entities become unified into the dynamic flow of experience. Process-ontological theories, in contrast, purportedly can capture both the dynamism and relative stability of personhood in virtue of processes alone, without mysterious postulations. 
Third, and relatedly, process-ontological theories claim to be more parsimonious than rival theories. Process ontologists conceive of persons and their persistence solely in terms of one fundamental kind - processes - in contrast to more familiar ontologies that postulate multiple kinds, such as particular substances, universal substantial kinds, particular properties, and universal property kinds (see Lowe). Finally, process-ontological theories claim to be able to account for the dynamicity of personhood in a more satisfactory way than traditional conceptions of dynamicity (namely, as reducible to changes in things or objects), since personhood prima facie is not object based (McGilvray 245). Process-ontological theories may therefore have greater explanatory power (Sellars 55), since the constancy in the flux that is a person (57) could be accounted for by conceiving of a "person [as] a bundle of absolute processes" (87).

With these considerations serving as a background, I will now introduce, interpret, and develop two incompatible process-ontological theories of personal identity. The first theory derives from the notion of personal identity proposed in Whitehead's metaphysics, but I interpret this notion differently from previous commentators. The Whiteheadian theory may appeal to those who believe that personal identity involves an entity or entities that are essentially dynamic, but has nothing to do with diachronic objectual identity. The Whiteheadian theory may also find favor with those who, like Whitehead, reject the possibility of pure processes and hold that in every becoming, something - which need not be an object, thing, or individual substance- - becomes. When we say that persons come to be, undergo change, and eventually cease to be, what makes our assertions meaningful, from a Whiteheadian point of view, are relationships of diachronic continuity and unity that obtain between numerically distinct token-events of a "personal" type. As such, a person, on Whitehead's view, is not one entity that remains one and the same over time. Rather, personhood involves specific relationships that unify many entities-where such entities are essentially processual.

The second theory derives from the notion of recurrent dynamics presented in Seibt's General Process Theory. The Seibtian theory may appeal to those who believe that personal identity involves not only an entity or entities that are essentially dynamic, but also the relation of diachronic objectual identity. The Seibtian theory may also find favor with those who, like Broad and Sellars, find reason to postulate pure processes. Whereas Whitehead explains personal identity in terms of the diachronic 
continuity and unity that obtain between non-identical person-entities, Seibt conceives of personal identity as involving one and the same determinable, dynamic individual recurring at different moments. What a person is at any given moment, according to Seibt, is a generic, subjectless process that forms one part of a bundle of subjectless processes. Those pure processes interfere with the person in various ways; and what it means for a person to persist is for a person-process to survive the interferences with which it occurs at different moments.

Given that my aim is to introduce and develop these theories, I will not attempt to adjudicate which is preferable. The purpose of this article is exploratory, not evaluative. I note in passing, however, that if Wittgenstein, Hintikka, and Wehmeier are right that objectual identity is both logically and ontologically dispensable, then the Whiteheadian theory would have at least this advantage over Seibt's: it relies in no way on the concept of diachronic objectual identity, and indeed rules out the possibility of such a "relation."

\section{Whitehead's Theory of Personal Identity}

Whitehead's theory of personal identity forms one part of an intricate system. Accordingly, it will be necessary to introduce several technical notions that enter into its formulation (though I will have to neglect many others): actual entities, societies, subjective forms, and formless receptacles. The notion of formless receptacles, I will argue, plays a central role in Whitehead's account, yet it has been neglected by previous interpreters.

Whitehead employs the technical terms "actual entity" and "actual occasion" to refer to the most basic elements of temporal reality. (He employs the term "eternal object" to refer to the most basic element of atemporal reality.) Actual entities are ontologically basic, in that they "are the final real things of which the world is made up. There is no going behind actual entities to find anything more real" $(P R$ 18). Actual entities are atomic, in this sense: they are the basic, ontologically indivisible items by which anything whatsoever is constituted.

Actual entities often compose more complex units, including societies, which are organized complexes of many actual entities. Societies differ from actual entities in that they are self-sustaining, persist, and have a history; and persons count as a specific kind of society (AI $233 \mathrm{ff}$.). Before we examine what kind of society a person is, however, I need to introduce some of the abstract structures that enable actual entities and 
societies to come into being. Grasping the complementary functions of these structures will enable us to appreciate the personal identity of a person qua society.

Whitehead holds that although actual entities qua atoms are ontologically indivisible, the power of intellectual abstraction enables us to analyze an actual entity "into modes of functioning which jointly constitute its process of becoming" ( $A I$ 176; PR 219). This formulation reminds us that the category of actual entities is a process-ontological postulate: actual entities are dynamic processes, are receivings of aspects from past occasions, and are not the ontologically derivative doings of substance-like particulars. Unlike traditional substances, moreover, the actual entities that Whitehead describes cannot persist beyond the moment that they come into being. No two actual entities are ever identical, since every receiving at every moment is ontologically distinct from all others. Whitehead often expresses this thesis by claiming that every actual entity is novel and absolutely individual: every occasion is both self-identical and numerically distinct from all other occasions of becoming. Correlatively, Whitehead's axioms rule out the possibility of synchronic and diachronic objectual identity.

That said, the novelty of every occasion does not entail that they are ontologically isolated, "windowless monads." The fact that actual entities are syntheses of aspects taken from past occasions means that there can be, and often is, significant continuity between distinct occasions. Part of what it means for an actual entity to be essentially dynamic is that its mode of being is a novel synthesis of aspects inherited from other occasions, which subsequently can contribute aspects of itself to the becoming of future occasions. Whitehead expresses this thesis idiomatically by claiming that actual entities are subject-superjects:

It is fundamental to the metaphysical doctrine of the philosophy of organism, that the notion of an actual entity as the unchanging subject of change is completely abandoned. An actual entity is at once the subject experiencing and the superject of its experiences. ... It has become a 'being'; and it belongs to the nature of every 'being' that it is a potential for every 'becoming.' ( $P R 43 \mathrm{ff}$.)

Any entity is a subject, in that it is that which becomes in its atemporal, "algorithmic" process of synthesizing aspects inherited from other occasions (Smith 219ff.). Every entity is also a superject, in that what becomes - the entity as subject — can allow aspects of itself to be inherited 
by future entities. More specifically, entities' superjective character enables the same aspects - not entities - to be transmitted repeatedly in future occasions; and this, in turn, makes possible the continuity and connectedness of nature. The fact that relations of continuity can obtain between numerically distinct occasions of experience is crucial for Whitehead's theory of personal identity, for it is in virtue of the continuity between distinct experiences that they may become cohesive parts of one (whole) life.

However, if every temporally basic item is an activity that differs from all others, including even its immediate predecessors and successors, then how is diachronic continuity possible? In particular, how can relations of continuity obtain between token occasions of the personal type? Here we are not so far from what perplexed Hume: how distinct items-in Hume's case, perceptions, and in the present case, actual occasions-can be really and not just imaginarily connected.

Whitehead's technical term for what makes diachronic continuity possible is an entity's "subjective form"; and he claims that every entity necessarily has some subjective form that provides the pattern for that entity's becoming. ${ }^{1}$ Consider your experience at the present moment, for example. (Note, however, that "subjective" in "subjective form" need not imply the subjectivity of a conscious personality. Even non-conscious entities such as quarks are supposed to have subjective forms.) On Whitehead's view, your conscious and unconscious beliefs, desires, intentions, values, dispositions, emotions, and so on, shape the way in which you are experiencing your environment at this moment. A difference in the underlying form of your experience - say, if you were extremely thirsty—-would necessarily entail a difference in the qualitative character of your experience. Were you thirsty, the words on this page would seem less interesting than a glass of water, and you might fixate on water at the cost of focusing on the text. The entire "affective tone" of your experience would differ; and Whitehead would explain this difference in tone in terms of differences in the underlying form of your experience-how you are experiencing the present moment. Taking this example as one paradigm of a complex actual occasion, Whitehead holds that any occasion whatsoever has the content or "matter" of its being shaped or "formed" by underlying possibilities, dispositions, tendencies, and so on.

Subjective forms serve at least two important functions, which are necessary for the possibility of personal identity. First, an entity's subjective 
form provides the shape or "form" for the content or "matter" of that entity's becoming. Whitehead conceives of actual entities as determinate unities of otherwise diverse aspects that have been "prehended" from past occasions. For diverse aspects to become determinately unified into a new occasion, and thus for an occasion of experience to be possible, these prehended aspects must be unified in some way-that is, commensurately with some form. For me to have a meaningful experience, for example, a multiplicity of sensuous, cognitive, and other data must acquire a relatively unified shape. In the absence of such a shape, a way for the multiple to be integrated into one, it would not be possible for there to be any experience, let alone this experience of writing here, now.

The upshot for Whitehead's theory of personal identity is that the $a$ priori conditions for the possibility of experience include some form that a putative experience may take. A person can enjoy an experience only if there are some background conditions-beliefs, desires, intentions, values, dispositions, tendencies, emotions, and so on-that enable the experience to occur.

The first function that subjective forms serve, then, is to make synchronic unity possible: they enable diverse contents to acquire determinate shape at specific moments. Subjective forms also fulfill a second function: they make diachronic continuity possible. Imagine listening to a rapturous musical performance. The performance consists of moments that follow one another in immediate succession, and we experience the performance as being continuous throughout this succession. The continuity of our experiences naturally gives rise to the belief that each moment is part of one and the same (whole) performance; and we ordinarily refer to such continuous occurrences as one event, as in "the life-changing freejazz performance that I witnessed at Chicago's Velvet Lounge in 2004.”

Whitehead maintains that such expressions, while sufficient for everyday life, are metaphysically misleading. For although we experience the performance as one temporally continuous event, in fact "the performance" denotes a series of distinct, novel experiences, none of which is identical to any other. The occasions of experience, furthermore, are not static, four-dimensional slices that somehow jointly constitute the experience as of a continuous performance. Rather, on Whitehead's view, the individual occasions are dynamic processes in their own right. The issue that Whitehead must address, then, is how absolutely distinct experiences can be diachronically continuous. 
Whitehead's response involves highlighting the aspects that recur in successive subjective forms. From a Whiteheadian point of view, diachronic continuity is possible precisely because the same parts of one whole subjective form can recur in the numerically distinct subjective forms that shape different moments (see Kraus 68). Take the anxiety one feels when watching a well-executed horror film, for example. The sense of anxiety accompanying each moment of the film is possible because of an element that recurs in the subjective forms underlying each moment of watching the film: namely, a disposition towards feeling anxious. Put differently, it is in virtue of the recurring disposition towards anxiety that a person's experiences can be continuous across different moments. Generalizing from this specific case: Whitehead claims that we experience multiple events as continuous precisely because of various elements that recur in the subjective forms underlying those events. What matters is not identity of subjective form, but elements that recur in numerically distinct subjective forms.

Fittingly, the doctrine of novelty, which I introduced above in connection with actual entities, applies also to subjective forms: “.... in the becoming of an actual entity, novel prehensions, nexuses, subjective forms, propositions, multiplicities, and contrasts, also become" (PR 22). Although one part of a whole subjective form may fulfill a common function in several successive occasions, and thus be said with qualification to remain "the same" over time, this does not entail that whole subjective forms can remain identical over time. The doctrine of novelty expressly forbids that possibility.

The upshot of this interpretation for Whitehead's theory of personal identity is that subjective forms make possible both the synchronic unity of a personal experience, and the diachronic continuity of multiple personal experiences. Both of these functions are necessary for the possibility of personal identity. I contend that they are not jointly sufficient, however; for on their own, subjective forms are not capable of unifying unique experiences into the becoming of one whole life. What still needs to be explained is how distinct occasions of the person-type are not only synchronically and diachronically continuous, but also diachronically unified. That function, I claim, is supposed to be fulfilled-however successfully-by an abstract structure that Whitehead discusses in Adventures of Ideas: formless receptacles.

Whitehead explicitly takes the "inescapable fact" of personal unity, 
not identity of subjective form, to lie at the heart of personal identity:

In our account of human experience we have attenuated human personality into a genetic relation between occasions of human experience. Yet personal unity is an inescapable fact .... Evidently there is a fact to be accounted for. Any philosophy must provide some doctrine of personal identity. In some sense there is a unity in the life of each man, from birth to death. (AI 186)

Whitehead would grant that belief in personal identity as identity is constitutive of human experience. But Whitehead would also insist, here in qualified agreement with Hume, that strong belief in a simple and identical self does not prove the existence of such a self. On the contrary, Whitehead would maintain that belief in personal identity as identity is partly grounded in the synchronic unity and diachronic continuity made possible by subjective forms. Indeed, Whitehead holds that our consciousness of the self-identity that pervades the "life-thread" and "personal order" of our experiences provides us with direct knowledge of the synchronic unity and diachronic continuity of experience. He also maintains that past subjective forms of self-experience are almost always continuous with those of the present (AI 183). But personal identity, for Whitehead, has nothing to do with identity per se. Personal identity is a matter of diachronic unity.

Several interpreters have criticized Whitehead's theory of personal identity for failing to accord with the commonsense belief that judgments about personal identity involve identity, and not merely relations of unity and continuity. Cobb, for example, has argued that since Whitehead's theory of personal identity categorically precludes the possibility of objectual identity through time, it poses serious difficulties for any doctrine of life after death, and

It poses many other problems as well. Our ordinary moral and legal practice presupposes personal identity. If there is no such personal identity, all justification for rewards and punishments seems to vanish. It would seem that there is no particular necessity to accept responsibility for our past acts, since they were performed by numerically different entities. Gratitude would seem to be misdirected when expressed after the moment of the beneficent act. Past promises would not bind. This list of consequences is endless and disastrous. (Cobb 35ff.)

Although Cobb rightly points out Whitehead's lingering concern as to 
whether his system provides an adequate account of personal identity, I believe that Cobb, Weiss, Sherburne, and others have overlooked how Whitehead addresses his own concern-namely, by introducing an abstract structure, the sole function of which is to unify ontologically and temporally distinct occasions. For this reason, the key to understanding Whitehead's theory of personal identity lies in grasping the complementary functions that subjective forms and formless receptacles fulfill for persons, qua societies of a specific type.

Whitehead delivers his most explicit characterization of personal identity by adapting a passage from Plato's Timaeus, claiming that "it is impossible to improve upon" Plato's passage. Whitehead's adaptation makes liberal use of the notion of a receptacle, which he derives from Plato's more general "Receptacle or Locus whose sole function is the imposition of a unity upon the events of Nature" (AI 187). ${ }^{2}$ Like Plato's Receptacle (capital 'R'), which imposes unity upon all events by making them part of the same universe, a person's receptacle (small ' $r$ ') imposes unity upon the events of his or her life. A person's receptacle, in other words, makes it such that distinct occasions become and are experienced as constitutive parts of one whole life. A person's receptacle is formless, however, in that it does not require any specific kind of experience or unification to take place. On account of a person's receptacle, any token experience of the personal type becomes a constitutive part of that person's life, no matter how discordant that occasion may be with the person's previous experiences, beliefs, desires, intentions, values, dispositions, tendencies, and so on. Whitehead expresses this idea by contending that a person's formless receptacle receives "all manners of experiences into its own unity," without imposing conditions on what that unity must consist in (AI 187). Whitehead assigns the latter function of imposing specific conditions, as we have seen, to subjective forms (and eternal objects, given the constraints that they impose on potential prehensions). A person's receptacle, in contrast, is simply that in virtue of which the person's experiences belong to one and the same life; and it fulfills this function by unifying ontologically and temporally distinct occasions of the personal type.

Because Whitehead introduces the notion of a formless receptacle specifically to explain how personal experiences become diachronically unified, the introduction of formless receptacles may seem ad hoc. I will not pursue that criticism here. ${ }^{3}$ 
Given Whitehead's doctrine of novelty, it would be wrong to think that a person's formless receptacle remains identical over time, and thereby serves as the diachronically identical substrate to which all of a person's experiences belong. Fittingly, Whitehead explicitly rejects the notion that a person's receptacle could remain identical over time, for the receptacle "of the becomings of the occasions of our experience" is itself "changed and variously figured by the things that enter it; so that it differs in its character at different times" (AI 187). Any experience that enters into a receptacle alters both the receptacle itself and the person's history, without having to conform to specific conditions as to what that history must be. For this reason, Whitehead sometimes refers to receptacles as "the fostermother... of the becoming of our occasions of experience" (187). Receptacles are foster-mothers, in that they receive any experience and unify it with a person's previous experiences. A person's receptacle can thus be said to "persist" only insofar as it performs the same function at different moments. Further, receptacles are individuated - not as actual entities, but as abstract functions - by what they do: unifying the actual occasions that enter into them, even as those occasions change and variously figure that into which they enter.

The interpretation that I have been developing might lead one to think that persons are formless receptacles. But that cannot be right: persons and receptacles exhibit different formal features. Persons are not receptacles; persons have receptacles. Receptacles perform a crucial function for persons; namely, unifying distinct experiences.

I have claimed that receptacles function as loci of diachronic unity for persons. But I have not yet explained what persons are, such that synchronic unity of individual experiences, and diachronic continuity and unity of between multiple experiences, is possible. For the sake of brevity, I will answer by introducing five conditions, each of which specifies its predecessor.

First, persons are not actual entities per se, but societies (see Leclerc 66). Societies are organized complexes of actual occasions that exhibit more internal structure than mere set-theoretical gatherings (see Hartshorne $177 \mathrm{ff}$.). Furthermore, unlike actual occasions, which cannot persist beyond the moment at which they come into existence, societies necessarily are temporally extended, self-sustaining, and have a history. As Whitehead puts it, "the society, as such, must involve antecedents and subsequents. In other words, a society must exhibit the peculiar quality of endurance" 
(AI 203). At this point it should be clear that endurance, as Whitehead conceives of it, has nothing to do with endurantism, three-dimensionalism, or objectual identity. Rather, Whiteheadian endurance concerns the recurrence of various elements in the subjective forms of a society's experiences.

Second, as societies, persons satisfy a particular genetic condition on how they endure through time (see Wallack 91). Specifically, persons exhibit social order, meaning that every occasion of the society's becoming exemplifies some defining characteristics that differentiate the society as both the type and token process that it is. A person exhibits social order, then, in that: (i) the defining characteristics of the immediate past partially constrain the person's present becoming; and (ii) the defining characteristics of the present partially constrain the person's future becomings (see Hartshorne 181). Persons not only maintain themselves via the preservation of their defining characteristics, but also impose constraints - via subjective forms - on what future occasions can count as parts of one and the same society. This is what it means for persons qua societies to be self-sustaining.

Third, persons are societies that exhibit not only social order, but personal order. Persons exhibit personal order, in that their experiences are serially ordered and follow immediately from their predecessors: “ . . personal order means one-dimensional serial order" (AI 188). The fact that a person's successive experiences exhibit one-dimensional serial order makes it possible for a continuous thread of inherited characteristics to endure through them. This is crucial for Whitehead's theory, because the linear seriality of a person's experiences makes it possible for that person's formless receptacle to unify the experiences into one life.

Fourth, persons are personal societies that exhibit the relative dominance, central direction, and unified control of a central personality or intelligence. When I will my body to move in various ways, for example, the living structured nexus of occasions that my body is obeys the intentions directed at it by my central intelligence. This applies not only to my physical body, however, for I can also take control of myself emotionally, and thereby introduce not only physical, but cognitive novelty into the flow of my experience. Such forms of control are characteristic of personhood.

Conditions one through four are still not jointly sufficient to characterize human persons, however, for animals such as chimpanzees and dolphins may exhibit all of the aforementioned features. For this reason, 
a fifth and final condition is needed: the capacity for self-consciousness.

In the case of single cells, of vegetation, and of the lower forms of animal life, we have no ground for conjecturing living personality. But in the case of the higher animals there is central direction, which suggests that in their case each animal body harbours a living person, or living persons. Our own self-consciousness is direct awareness of ourselves as such persons. (PR 107)

Fifth, then, persons have the capacity for self-consciousness: that is, awareness of themselves as societies that meet conditions one through five. To be self-aware, in the Whiteheadian sense, is to recognize oneself as a society that involves an influx of the other into the self-identity of the present, yet can persist through such changes by integrating them and introducing novelty through intentional action (AI 181).

Putting everything together, we have arrived at an interpretation of Whitehead's theory of personal identity that does justice both to $P R$ and the supplementations introduced elsewhere, particularly in $A I$. On Whitehead's view, personal identity has nothing to do with objectual identity, but rather concerns the diachronic unity of novel experiences. The diachronic unity of human experience is made possible by a formless receptacle that belongs to each person - that is, to each personal society that exhibits a central intelligence, and is capable of recognizing itself as such an intelligence. Formless receptacles are not sufficient for personal identity, however, for human experience is also synchronically unified and diachronically continuous; and subjective forms enable human experience to be synchronically unified and diachronically continuous. Consequently, subjective forms and formless receptacles are jointly sufficient for personal identity - with the qualification that the kind of entity that undergoes the experiences meets conditions one through five.

\section{Seibt's Theory of Personal Identity}

Although Seibt has not published an extended treatment of personal identity, we can infer the essentials of such a theory from the notion of recurrent dynamics that forms the basis of her process-ontological theory of persistence. Like's Whitehead's theory, Seibt's theory of persistence is one part of an intricate system; so it will be necessary to introduce several features of Seibt's system to appreciate what it has to offer.

Seibt develops her system in opposition to substance ontologists and 
even Whitehead, for she criticizes them for failing to recognize the categorial separability of individuality, countability, and particularity. Seibt's Sellars-inspired criticisms derive from meta-linguistic factors concerning the "category implications" of the denotations of mass nouns and activity verbs, and the corresponding categorial inferences that she takes to be licensed in English and its truth-functional translation equivalents. For present purposes, we can set aside the details of these analyses. The important point is that recognizing the separability of the aforementioned category features, according to Seibt, enables one to postulate kinds of entity that otherwise seem inadmissible-specifically, entities that are not only essentially individual, but also non-countable and non-particular.

The two suppositions that have most detrimentally hindered analytic ontology, Seibt contends, are the following:

(SUB1) Principle of Individuality: All and only concrete individuals are countable, determinate particulars.

(SUB2) Principle of Categorial Dualism: An entity is either particular or general (universal), and never neither nor both. ${ }^{4}$

Seibt argues that (SUB1) and (SUB2) are overly restrictive "linkage principles" that preclude certain modes of being from characterizing the same kind of entity. For example: if all and only individuals are particulars (SUB1), then an entity's individuality - its ontological distinctness from other entities - necessarily implies its particularity, that it necessarily occurs in only one spatiotemporal location whenever it occurs. If all individuals are particulars, moreover, and any entity must be either a particular or a universal (SUB2), it follows that no individual can be general: potentially occurrent in different spatial regions at the same time.

In opposition to (SUB1) and (SUB2), Seibt-following Sellars (87) - develops a system that postulates only one fundamental kind: dynamic individuals that are non-countable, determinable, and general. Seibt explicitly distinguishes her process-ontological system from Whitehead's. Whitehead allegedly employs (SUB1), because what it means to be an actual entity is not only to be an individual that is distinct from all others, but also and necessarily a concrete, countable, particular, and determinate individual. Whitehead also purportedly employs (SUB2) — and this, despite his insistence on the inadequacy of the traditional distinction between particulars and universals (PR 20, 48ff.) - because he postulates two mutually exclusive, fundamental kinds: actual entities, which are particular; 
and eternal objects, which are general.

Seibt argues that modes of being that have traditionally been thought to be either necessarily co-extensional (such as individuality, countability, particularity, determinateness, concreteness, etc.), or necessarily mutually exclusive (such as particularity/generality, concrete/universal, etc.), are not. Denying (SUB1) and (SUB2) enables Seibt to postulate a novel kind of entity, general processes, which are individual, non-countable, non-particular, determinable, and functional, as opposed to spatiotemporally individuated. Seibt goes on to claim that general processes ontologically ground and adequately explain all other kinds, including medium-sized dry goods and persons; so fittingly, Seibt refers to her system as "General Process Theory," or GPT, for short.

In addition to recognizing heretofore inadmissible combinations of category features, the second putative advantage of GPT is its alleged parsimony and explanatory power. Seibt contends that GPT provides truthmakers for all of our categorial inferences, including those we make about non-countable masses and subjectless activities; and that it does so by postulating only one fundamental kind and one fundamental relation: namely, a non-classical, non-transitive "part of" relation, in virtue of which overlapping general processes can constitute higher-level entities such as persons ("Dynamic" 252ff.). A third putative advantage of GPT is that its theory of persistence allegedly "transcends" and obviates recalcitrant debates between endurantists and perdurantists. At the same time, Seibt's theory of recurrent dynamics is supposed to more adequately capture the dynamicity that is characteristic of spatiotemporal existence, including the dynamicity of personhood.

To describe a theory of personal identity that is consistent with the core theses of GPT, it will be helpful to examine the material phenomena that general processes are supposed to represent: subjectless activities. In contrast to substance ontologists, who take things to accurately reflect ontological structure, and Whitehead, who purportedly takes minds to accurately reflect ontological structure, Seibt proposes a model that is supposed to account for a much wider range of phenomena, and more accurately and adequately at that. An activity, as Seibt conceives of it, is not an abstract type, but a concrete mode of occurrence, a way of occurring: "Our concept of an activity is the concept of how something is happening ("Free" 31). Seibt recognizes that some activities are constitutively tied to subjects. But other activities, Seibt claims, are patently subjectless, 
in that there is no bearer that necessarily participates in the occurrence, no determinate that-to-which the activity in question necessarily belongs. A subjectless activity, then, is some determinable way of occurring in space and time, in relation to which there is not necessarily some thing or person that owns or undergoes the process. In Seibt's words, a subjectless activity "is an occurrence that might involve, but is not, the doing or acting of a person or thing (or of a collection of persons or things)" ("Beyond" 147). Subjectless activities are thus supposed to be identity independent, "in the sense that their occurrence in space and time does not necessarily require the existence of a different sort of entity they occur in or qualify" ("Particulars" 48). Clearly, the conception of process that Seibt employs differs markedly from that of substance ontologists, according to whom processes essentially and asymmetrically depend for their identity on essentially independent particulars, such as individual substances.

Like Sellars, Seibt finds evidence for the existence of subjectless activities - qua truth-makers - in sentences that have dummy subjects, such as "it is buzzing," "it is raining," "the fire is burning," and "electromagnetic radiation is traveling through empty space." Indeed, Seibt holds that sentences with dummy subject terms are meaningful precisely because subjectless activities exist and serve as the denotations of such subject terms. Seibt finds further evidence for subjectless activities in the language we use to describe force-like natural phenomena, such as shifts in barometric pressure, the Hubble expansion of the universe, and so on (see Rescher 5). ${ }^{5}$

Crucially, what individuates a subjectless activity is its distinctive mode of occurrence - that is, its purely functional or qualitative character relative to some dynamic context-and not its spatiotemporal location: "Subjectless activities are individuated in terms of their role within a dynamic context, rather than by their location in space and time" ("Particulars" 48; also see "Process" 20). This claim is crucial for Seibt's purposes, for she takes this fact about how subjectless activities are individuated to entail that they are not only concrete, like traditional particulars, but also multiply occurrent, like traditional universals - and this directly contravenes (SUB1) and (SUB2):

non-countables are both or neither particular and general entities. Masses and activities, the prime examples of non-countables, have concrete physical properties and are thus concrete; but they are 
multiply occurrent like general entities-you and I, we may have the same stuff in our glasses and when we drink from them we engage in the same activity. ("Dynamic" 249)

Since subjectless activities can involve either zero or many different spatiotemporal particulars, Seibt infers that one and the same subjectless activity (e.g., flowing or bubbling) or dynamic mass (e.g., water or wine) can occur in several, distinct, and possibly disjoint spatial regions at the same time.

The fact that subjectless activities are functionally individuated is also supposed to entail that they can recur at different moments. Subjectless activities are general or multiply occurrent, then, in that they can occur in multiple spatial locations at the same time, and recur at multiple moments. The upshot for the GPT theory of personal identity, as we will see, is that the persistence of persons amounts to one and the same dynamically individuated, multiply occurrent individual recurring at different moments. What a person is, according to GPT, is a spatiotemporally extended, non-countable, determinable individual that is individuated by how it functions in dynamic contexts - that is, the distinct way in which it occurs in space and recurs over time.

Take yourself, for example. Seibt holds that you are (literally) a general, dynamic, individual mode of occurrence that interferes with its environment in a way that is functionally, qualitatively, and numerically distinct from all other entities - that is, processes. No other process interferes with its environment in exactly the same way as you; and the way in which the processes in your environment interfere with you differs from the way in which they interfere with any other entity, including other persons. Seibt also maintains that you are essentially a determinable, and not a determinate kind of being. Your determinable qualities-your dispositions, tendencies, and so on-become determinate when you interfere with other general processes, such as the process of raining and the process of singing, which compose the bundle of pure processes denoted by "I was singing in the rain (there, then)." In this way, the functional and qualitative features that individuate you, and make you the very entity that you are, occur at the same time, and in the same spatial region, as other processes that further determine your relatively general features. To express the point in Seibt's idiom: concurrently occurring processes destructively, neutrally, or constructively interfere with the dynamic individual that you 
are and remain, even as those specific determinations change or cease.

Accordingly, in GPT, processes of change are tantamount to processes of interference. If you are pensive at $t_{1}$, relieved at $t_{2}$, and elated at $t_{3}$, for example, then there is one dynamic, relatively generic individual-you-that recurs throughout that interval, even as other processes (which cause you to be pensive, relieved, and elated, respectively) interfere with you. Such interfering processes are said to be specifications or further determinations of your essential features. To persist through change, then, means to dynamically survive various interferences at multiple levels of specification. These interferences include the most determinate kind of interference, termed ultimate specifications, which are so inextricably interwoven with a single moment that they cannot survive beyond it. The dynamic individual denoted by "Phenomenally, here, now, in this very experience, I perceive the lush growth of my grandmother's rubber plant outside of my window," for example, is ultimately specific in virtue of the indexicality of "here," "now," and "this" (see Smith). It cannot recur at another moment. At best, it can closely resemble other ultimately specific processes that occur at immediately preceding and successive moments. The relatively generic, dynamic individual denoted by "I," in contrast, can and does recur at other moments.

The upshot for Seibt's conception of personal identity is that a person changes by interfering with relatively specific dynamics at different moments, and survives by recurring relatively "generically" at each of those moments. Personal identity thus involves one and the same generic individual recurring at multiple moments of time, concurrently with specifications of that person-process which destructively, neutrally, or constructively interfere with it. As such, the GPT conception of personal identity is the kind of bundle theory of personal identity that Sellars envisioned in his initial reflections about absolute processes (Sellars 87).

Seibt maintains that personal identity must be understood in terms of the relation of objectual identity, rather than diachronic unity ("Dynamic" 275; "Beyond" 134, 158ff.). In contrast to Whitehead, then, for whom diachronic identity is ipso facto impossible, and for whom a part of a whole may remain "the same" only in a qualified sense, Seibt holds that numerically the same generic process may recur on multiple occasions.

What we need to complete the GPT account of personal identity are the kinds of conditions we covered above in connection with Whitehead. Seibt has not yet provided such conditions. If medium-sized dry goods 
and indeed all potentially persistent entities are generic processes, however, then we need an account of what distinctive dispositions, tendencies, and capacities would serve to differentiate persons from other types of persistent entities. The GPT conception of personal identity entails that persons are "spatially minimally homomerous"- that is, that none of a person's parts is a process of the same, relatively high level as the person herself. This might lead one to think that minimal homomerity in space constitutes a person qua person. The feature of minimal homomerity in space, however, is not sufficiently explanatory to individuate persons qua persons, for medium-sized dry goods also (allegedly) exemplify this feature. One charitable line of interpretation might follow the sketch suggested above, and define a GPT-person as a distinctive set of dispositions, tendencies, etc., that acquire further determination through various interferences. But until we know precisely what makes a GPT-person a person, and not some other kind of entity, it will remain unclear as to whether Seibt's distinction between generic and specific processes is absolute or relative; and thus whether that distinction, so understood, is adequate to the task of explaining how persons survive the inexorable flux of existence in time.

\section{5. "Revisionary" Metaphysics}

P. F. Strawson characterizes projects such as Aristotle's, Kant's, and his own as instances of descriptive metaphysics, which aims "to lay bare the most general features of our conceptual structure," that is, the "categories and concepts which, in their most fundamental character, change not at all" (Strawson 9-10). Strawson conceives of revisionary metaphys$i c s$, on the other hand, as being concerned to produce better conceptual structures. Yet even the best revisionary theories, by Strawson's lights, are valuable only insofar as they are "at the service of descriptive metaphysics" (ibid.). The implication is that descriptive metaphysics reveals actual structure (see Kriegel $1 \mathrm{ff}$.), whereas revisionary theories are useful only instrumentally, insofar as they remind us of the inexorable categories and concepts of descriptive metaphysics, which "[need] no justification at all beyond that of inquiry in general" (Strawson 9). One concept of descriptive metaphysics, Strawson goes on to claim, is that there is "a general identifiability-dependence of processes which things undergo upon the things which undergo them, and not vice versa" (57). Concordantly, standard substance ontologies, such as Aristotle's, Kant's, 
Ingarden's, P. F. Strawson's, Lowe's, et al., count as descriptive, whereas non-standard ontologies are revisionary, hence valuable only insofar as they remind us of the permanent categories and concepts presupposed by "our" universal conceptual structure - the structure described by substance ontology.

I find it doubtful that the distinction between descriptive and revisionary metaphysics is as sharp as Strawson suggests; and it is questionable whether the distinction is of any philosophical utility. Regardless, the salient point is that it can be extremely useful to examine "revisionary" theories, even if one is convinced, as so many are, of the accuracy and adequacy of substance ontology. The reason is that examination of revisionary theories either clarifies the descriptive categories and concepts that underlie thought per se, and thus is of instrumental value; or introduces genuinely new categories and concepts for thought, and thus is of intrinsic value. This reminds us of Mill's spirited defense of what one might call revisionary or radical inquiry:

since the general or prevailing opinion on any subject is rarely or never the whole truth, it is only by the collision of adverse opinions that the remainder of the truth has any chance of being supplied. [And] even if the received opinion be not only true, but the whole truth; unless it is suffered to be, and actually is, vigorously and earnestly contested, it will, by most of those who receive it, be held in the manner of a prejudice, with little comprehension or feeling of its rational grounds. (Mill 50)

Here I have attempted to occasion two collisions of the kind that Mill envisioned. I have done so, moreover, with reservations about the viability of process ontology. Is it conceivable that processes alone-whether of the Whiteheadian or Sellarsian/Seibtian type-could be exclusively fundamental? Having reflected on the question for years, I am still uncertain. Is it metaphysically possible that processes alone could be exclusively fundamental? Perhaps-but I must postpone an investigation of these issues for another occasion (Siakel, "Atemporal"). Regardless of how one answers these questions, however, process-ontological theories of personal identity provide compelling explanations of the dynamicity-and fragility—of personhood.

\section{ENDNOTES}

1. Subjective forms are determined by the eternal objects that an actual en- 
tity selects as being relevant to its becoming. More specifically, subjective forms receive their determination from a member of the subjective species of eternal objects, which "defines the subjective form of feeling of one actual entity" (PR 164, 291).

2. Whitehead claims that the essential function of Plato's Receptacle is marked by different terms in the philosophies of Lucretius, Descartes, and Leibniz (AI 150).

3. For a critical assessment of Whitehead's theory, as interpreted here, see Siakel, "Reassessing."

4. Seibt's way of numbering of the "twenty or so" substance-ontological presuppositions that she identifies differs, depending on the article. Apropos, the way in which I have designated (SUB1) and (SUB2) does not match all of Seibt's publications.

5. I worry that the notion of a subjectless activity may be inconceivable, if perhaps metaphysically possible. Throughout her work, Seibt does not provide an argument to establish the notion. Instead, she (like Sellars and Rescher) introduces contentious examples to motivate the intuition that bearerless activities exist. In every alleged illustration that Seibt provides, however, the process in question does seem to be constitutively tied to some subject or other, even if that subject or set of subjects changes over time, or that subject is merely some region of space-time. The processes that Seibt describes may not depend for their existence on one specific spatiotemporal particular or group of particulars; but they do seem to essentially and generically depend for their existence on some non-processual subject or other, in virtue of which those processes can occur. Indeed, it would seem to belong to the very nature of a process - even on purportedly revisionary conceptions of what a process is - to necessarily involve some subject or set of subjects, in virtue of which that process can exist as the kind of entity that it is. A fortiori, from the fact that some processes do not essentially depend for their existence on some specific entity or set of entities, it does not follow that processes per se are identity independent. For further elaboration of this worry, see Siakel, "Atemporal."

\section{Works Cited}

Bennett, John. "Whitehead and Personal Identity." Thomist 37 (1973): 510-21. Broad, C. D. Examination of McTaggart's Philosophy: Volume I. 1933. New York: Octagon, 1976.

Cobb, John. A Christian Natural Theology: Based on the Thought of Alfred 
North Whitehead. 1965. 2nd ed. Louisville: Westminster John Knox P, 2007. Gallois, Andre. "Identity Over Time." Stanford Encyclopedia of Philosophy (Summer 2012 Ed.). Ed. Edward Zalta. Online June, 2014.

Hartshorne, Charles. Whitehead's Philosophy: Selected Essays, 1935-1970. Lincoln: U of Nebraska P, 1972.

Hintikka, Jaakko. "Identity, Variables, and Impredicative Definitions." Journal of Symbolic Logic 21 (1956): 225-45.

Hume, David. A Treatise of Human Nature. 1739. Ed. David Norton and Mary Norton. New York: Oxford U P, 2000.

Ingarden, Roman. Controversy over the Existence of the World: Volume I.

1947. Tr. Arthur Szylewicz. New York: Peter Lang, 2013.

Kraus, Elizabeth. The Metaphysics of Experience: A Companion to Whitehead's Process and Reality. New York: Fordham U P, 1979.

Kriegel, Uriah. "The Epistemological Challenge of Revisionary Metaphysics." Philosophers' Imprint 13 (2013): 1-30.

Leclerc, Ivor. "Being and Becoming in Whitehead's Philosophy." In Explorations in Whitehead's Philosophy. Ed. Lewis Ford and George Kline. New York: Fordham U P, 1983: 53-67.

Lewis, David. On the Plurality of Worlds. 1986. Malden, MA: Blackwell, 2001. Lowe, E. J. The Four-Category Ontology: A Metaphysical Foundation for Natural Science. New York: Clarendon P, 2006.

McGilvray, James. "Pure Process(es)?" Philosophical Studies 43 (1983): 243-51. Mill, John Stuart. On Liberty. 1859. Ed. Elizabeth Rapaport. Indianapolis: Hackett, 1978.

Olson, Eric. "Personal Identity." Stanford Encyclopedia of Philosophy (Winter 2010 Ed.). Ed. Edward Zalta. Online June, 2014.

Parfit, Derek. Reasons and Persons. New York: Clarendon P, 1984.

Perry, John. Identity, Personal Identity, and the Self. Indianapolis: Hackett, 2002. Rescher, Nicholas. Process Philosophy: A Survey of Basic Issues. Pittsburgh: U of Pittsburgh P, 2000.

Seibt, Johanna. "The Dynamic Constitution of Things." Facts and Events: Poznan Studies in Philosophy of Sciences and the Humanities 76 (2000): 241-78.

."Free Process Theory: Towards a Typology of Occurrings." Axiomathes 14 (2004): 23-55.

. "Process Ontology." Metafisica e Ontologia. Ed. G. Imaguire. Munich: Philosophia Verlag, 2005: 1-27.

. "Beyond Endurance and Perdurance: Recurrent Dynamics." In Persistence. 
Ed. C. Kanzian. Piscataway, NJ: Transaction Books, 2007: 133-64. . "Particulars." In Theories and Applications of Ontology. Ed. Roberto Poli and Johanna Seibt. New York: Springer, 2010: 23-56.

Sellars, Wilfrid. "Foundations for a Metaphysics of Pure Process." Monist 64 (1981): 3-90.

Sherburne, Donald. "Responsibility, Punishment, and Whitehead's Theory of the Self." In Alfred North Whitehead: Essays on His Philosophy. Ed. G. L. Kline. Englewood Cliffs, NJ: Prentice Hall, 1963: 179-88.

Siakel, Daniel Robert. "Atemporal Processes and the Conceivability of Pure Processes." Forthcoming.

. "Reassessing Whitehead's Theory of Personal Identity: A New Interpretation and Critical Examination." Forthcoming.

Sider, Theodore. Four-Dimensionalism: An Ontology of Persistence and Time. New York: Clarendon P, 2001.

Smith, David Woodruff. Mind World: Essays in Phenomenology and Ontology. New York: Cambridge U P, 2004.

Strawson, Galen. Selves: An Essay in Revisionary Metaphysics. New York: Clarendon P, 2009.

Strawson, P. F. Individuals: An Essay in Descriptive Metaphysics. 1959. New York: Routledge, 2003.

Wallack, F. Bradford. The Epochal Nature of Process in Whitehead's Metaphysics. Albany: State U of New York P, 1980.

Wehmeier, Kai. "How to Live Without Identity-And Why." Australasian Journal of Philosophy 90 (2012): 761-77.

Weiss, Paul. "History and Objective Immortality." 1961. In The Relevance of Whitehead. Ed. Ivor Leclerc. New York: Macmillan, 2002: 318-32.

Whitehead, Alfred North. Adventures of Ideas. 1933. New York: Free P, 1967. . Process and Reality. 1929. Corrected Ed. Ed. David Ray Griffin and Donald Sherburne. New York: Free P, 1978.

Wittgenstein, Ludwig. Tractatus Logico-Philosophicus. 1921. Tr. D. F. Pears and B. F. McGuinness. New York: Routledge, 2001. 
Copyright of Process Studies is the property of Center for Process Studies and its content may not be copied or emailed to multiple sites or posted to a listserv without the copyright holder's express written permission. However, users may print, download, or email articles for individual use. 